\title{
Panorama brasileiro do ensino de contabilidade aplicada ao terceiro setor: uma análise nas instituiçoes públicas de ensino superior
}

\author{
Fernando Gentil de Souza, Alexsandro Romao do Nascimento, \\ Jessé Ovídio de Santana
}

\author{
Universidade Federal de Pernambuco - Brasil \\ Universidade Federal de Pernambuco - Brasil \\ Instituto Federal de Alagoas - Brasil
}

O presente artigo tem como objetivo é apresentar o panorama do ensino de Ciências Contábeis do terceiro setor (TS) no curso de Ciências Contábeis frente ao seu destaque e crescimento, espera-se que o ensino superior possa preparar o profissional para atuar com as recentes modificaçóes dá a legislação TS, preparando informaçôes úteis e transparentes para seus usuários. Para atingir o objetivo, foi verificada a oferta de disciplinas em instituiçóes de ensino superior (IES) no Brasil. O estudo empírico de natureza aplicada, tem como metodologia exploratória analisando a matriz curricular disponibilizada nas páginas de 77 IES públicas, sendo analisados 62 disciplinas ofertadas sobre o TS. Os resultados indicaram que a oferta da disciplina TS não ocorre em todas as IES no Brasil, as que possuem a disponibilizam como disciplina eletiva (optativa). A pesquisa destacou que dentre as IES estudadas a UNIFESP oferece a disciplina de TS com maior carga horária. Dentre a análise por regiôes os resultados apresentaram que a regiấo Nordeste e representados pelos estados da Bahia e de Minas Gerais, são os que mais ofertam disciplinas de TS. De acordo com o Instituto de Pesquisa de Economia Aplicada (IPEA, 2020) esta região e estes estados não são os que mais quantitativo de instituições do TS. Por fim, dados analisados revelaram que as IES no Brasil não estão atendendo a Resolução 4 de 2005 em sua totalidade.

Palavras-chave: ensino de contabilidade, contabilidade aplicada ao terceiro setor, ensino de contabilidade aplicada ao terceiro setor, currículo do curso de Ciências Contábeis

\section{Panorama brasileńo de la docencia contable aplicada al tercer sector: un análisis en instituciones públicas de educación superior}

El objetivo de este artículo es presentar el panorama de la docencia de las Ciencias Contables en el tercer sector (TS) en la carrera de Contabilidad dado su protagonismo y crecimiento, se espera que la educación superior pueda preparar al profesional para actuar con los recientes cambia la legislación TS, preparando información útil y transparente para sus usuarios. Para lograr el objetivo, se verificó la oferta de disciplinas en las instituciones de educación superior (IES) en Brasil. El estudio empírico de carácter aplicado tiene como metodología exploratoria analizar el currículo disponible en las páginas de 77 IES públicas, analizándose 62 asignaturas ofertadas en la ST. Los resultados indicaron que el curso de TS no se ofrece en todas las IES de Brasil, las que lo tienen disponible como curso electivo (opcional). La investigación destacó que entre las IES estudiadas, UNIFESP ofrece la disciplina TS con mayor número de horas. Entre el análisis por regiones, los resultados mostraron que la región Nordeste y representada por los estados de Bahía y Minas Gerais, 
son las que ofrecen más disciplinas de TS. Según el Instituto de Investigación en Economía Aplicada (IPEA, 2020), está región y estos estados no son las instituciones de TS más cuantitativas. Finalmente, los datos analizados revelaron que las IES en Brasil no están cumpliendo con la Resolución 4 de 2005 en su totalidad.

Palabras clave: contabilidad aplicada al tercer sector, docencia contable aplicada al tercer sector, panorama del tercer sector

\section{Brazilian panorama of accounting teaching applied to the third sector: an analysis in public institutions of higher education}

The aim of this article is to present the panorama of the teaching of Accounting Sciences in the third sector (TS) in the Accounting course in view of its prominence and growth, it is expected that higher education can prepare the professional to act with the recent changes gives TS legislation, preparing useful and transparent information for its users. To achieve the objective, the offer of disciplines in higher education institutions (HEIs) in Brazil was verified. The empirical study of an applied nature, has as exploratory methodology analyzing the curriculum available in the pages of 77 public HEIs, being analyzed 62 subjects offered on the TS. The results indicated that the TS course is not offered in all HEIs in Brazil, those that have it available as an elective course (optional). The research highlighted that among the HEIs studied, UNIFESP offers the TS discipline with the highest number of hours. Among the analysis by regions, the results showed that the Northeast region and represented by the states of Bahia and Minas Gerais, are the ones that offer the most TS disciplines. According to the Institute of Applied Economics Research (IPEA, 2020) this region and these states are not the most quantitative of TS institutions. Finally, data analyzed revealed that HEIs in Brazil are not complying with Resolution 4 of 2005 in its entirety.

Keywords: Accounting education, Accounting applied to the third sector, Accounting teaching applied to the third sector, Accounting sciences curriculum

\section{Introduçáo}

A contabilidade surgiu como sistema de informação capaz de suprir demandas da sociedade, descortinando para isto a realidade e os fenômenos patrimoniais que possam garantir a qualidade das informações contábeis (Sousa Araújo, Araújo Leal, \& Ferreira Lourenço, 2021; Araújo, Costa, Costa, \& Furtado, 2019; Iudícibus, 2010). Dessa forma, tendo como objetivo o alcance dos registros dos bens, até o acompanhamento e suporte à gestão patrimonial e financeira (Healy \& Palepu, 2001).

Entre as diversas áreas de atuação, a contabilidade se desenvolve para prestar informação para cada setor, com ou sem fim lucrativo. Nesse sentido, cabe ressaltar que o terceiro setor (em diante, TS) surgiu para suprir o que não podia ser oferecido nem pelo Estado (Primeiro Setor), nem pela iniciativa privada com fins lucrativos (Segundo Setor). Finalmente, o TS é representado pelo conjunto de entidades privadas sem fins lucrativos, que visam o bem estar-social (Jorge, 2020; Portulhak, Delay, \& Pacheco, 2015). Essas organizações são orientadas por valores sociais e alicerçadas em sua missão (Piza, Parisi, Megliori, \& Gallo, 2012; Hudson, 2002). Apesar de serem instituiçóes que possuem interesse público e finalidade social, não visam lucro e são regidas por um estatuto social, com a aquisição ou não capital para sua abertura (Souza, Barros, Celis, \& Araújo, 2021; Araújo et al. 2019; Zittei, Politelo, \& Scrapin, 2016; Souza, Dantas, Araujo, \& Silva, 2012).

Contabilidad y Negocios (16) 32, 2021 / ISSN 1992-1896 
Diante uma perspectiva institucional as atuações das entidades TS sofrem a influência de agentes externos, os quais são caracterizados como agentes institucionais, que simbolizam os atores sociais relevantes que atuam no desencadeamento processos de institucionalização de estruturas ou práticas organizacionais (Araújo, Leal, \& Lourenço, 2021; Silva \& Aguiar, 2011; Silveira \& Borba, 2010). Devendo ser considerado os atores, os significados e as açóes entre o contexto institucional das organizaçóes do TS e assim como os microprocessos organizacionais, (Goretzki, Strauss, \& Weber, 2013). Da mesma forma, que o ambiente em que estas organizaçôes encontram-se inseridas demandam e contemplam elementos internos e externos que interagem diretamente com a organização (Innocenti, Lunkes, \& Gasparetto, 2021).

Segundo o Instituto Brasileiro de Geografia e Estatística (IBGE, 2020), no ano de 2004 o TS se destacou pela primeira vez com sua participação no PIB brasileiro, sendo de 1,4\% do total do PIB, aproximadamente R\$ 32 bilhóes naquele ano. Deste modo o contabilista além de acompanhar as atividades das organizaçóes do TS, deve estar ciente que este setor contrata grande número de pessoas com nível superior. De acordo com o Censo IBGE (2017) cerca de um terço dos assalariados (33\%) destas entidades possuíam nível superior, enquanto a média nacional era de 16,6\% (IBGE, 2020).

De acordo com a Resoluçáo CNE/CES 10, de 16 de dezembro de 2004 em seu artigo $3^{\circ}$ inciso I, na graduação onde o futuro contabilista será capacitado a compreender as questôes científicas, técnicas, sociais, econômicas e financeiras, em âmbito nacional e internacional e nos diferentes modelos de organizaçôes (Conselho Nacional de Educação, 2004). Nesse contexto, a partir de insights teóricos da velha economia institucional, aborda uma discussão no envolto das relaçóes entre indivíduos e instituições ao longo do tempo, além do aumento, relevância social e as mudanças da contabilidade para essas instituiçóes do TS (Innocenti et al., 2021; Quinn \& Hiebl, 2018; Yazdifar, Zaman, Tsamenyi, \& Askarany, 2008).

Deste modo, torna-se necessário que a base educacional (graduação) de formação dos novos bacharéis em ciências contábeis sejam melhor preparadas para superar e acompanhar mudanças da contabilidade para estas organizaçóes. Principalmente, em razão da forma como são constituídas e os princípios norteadores dessas organizações, no contexto brasileiro (Jorge, 2020; Araújo et al. 2019; Soares, Richartz, De Lima Voss, \& De Freitas, 2012). Considerando as discussóes anteriores, o presente artigo tem o objetivo de apresentar o panorama sobre o ensino do TS na graduação em Ciências Contábeis. O estudo foi conduzido com o propósito de responder a seguinte questão norteadora: Qual é o panorama Brasileiro do ensino da Contabilidade Aplicada ao TS nos cursos de Ciências Contábeis das instituições de ensino superior (em diante, IES) públicas no Brasil?

O estudo se justifica pelo aumento, nos últimos anos, das entidades do TS e pelos impactos decorrentes de suas atividades na sociedade e os pressupostos existentes pela demanda por profissionais cada vez mais qualificados. Além do mais, os estudos o ensino de Ciências Contábeis do TS no curso de Ciências Contábeis permite uma reflexão sobre as transformações deste setor, que aconteceram ao longo do tempo, os quais de acordo com Gohn (2008) são marcados pelas mudanças de focos nos movimentos sociais na América Latina, que não limitam à política, à religião ou as demandas socioeconômicas e trabalhistas. $\mathrm{O}$ estudo permite compreender e se diferencia dos demais estudos da área por efetuar um panorama destas organizaçóes, principalmente no Brasil, além de entender 
as necessidades práticas dos futuros profissionais, na oferta da disciplina para TS, traçar um panorama da comunidade e ajudar a identificar possíveis soluçóes sociais. O estudo do terceiro setor torna-se cada vez mais oportuno devido seu papel dinâmico na sociedade, por ser um tipo de sociedade que reaviva uma sociedade civil ativa e participativa, que presa pelo interesse público e por proporcionar melhores serviços à comunidade (Araújo et. al., 2019). Ademais, o estudo do TS na graduação de ciências contábeis em diversos estudos (Jorge, Souza, \& Vendruscolo, 2021, Jorge, 2020; Mańas \& Medeiros, 2012, Albuquerque, 2006) argumentam que as instituiçóes sem fins lucrativos, como as associaçóes e fundaçóes, vem crescendo ao longo do tempo e há uma necessidade de uma demanda para este mercado, sendo assim necessário a formação de profissionais dedicados a esta área e saibam conhecer e lidar com este tipo societário que não visam lucro.

Para desenvolver essa pesquisa, após essa breve introduçáo, o trabalho se organiza da seguinte maneira. $\mathrm{Na}$ próxima seção são apresentados os antecedentes e referenciais sobre o tema, um pequeno panorama sobre a História da Educação em Contabilidade no Brasil. Em seguida, a metodologia e os principais resultados. Por último, são apresentadas as considerações finais deste trabalho.

\section{Antecedentes}

\subsection{A estrutura do terceiro setor}

Há três tipos de setores econômicos nos quais são classificadas as mais diversas estruturas associativas (Araújo, Pires, \& Farias Filho, 2018). O primeiro setor diz respeito às organizaçóes de administração pública, enquanto o segundo setor corresponde às do setor privado, e, por fim, o terceiro diz respeito às empresas de administração privada, mas sem fins lucrativos e outras particularidades, como afirma diversos autores (Innocenti et al., 2021; Silveira \& Borba, 2010; Scott, 1995; Falconer, 1999). Neste sentido, o TS é composto das entidades sem fins lucrativos, cuja administração é essencialmente privada, porém o fim é o público para toda a sociedade, não podendo, portanto, obter lucros frente às suas atividades desenvolvidas (Araújo et al., 2019; Quinn \& Hiebl, 2018).

Para melhor definir o TS, é comumente utilizada uma série de fatores elencados por Salamon e Anheier (1992, 1993) definindo suas respectivas estruturas organizacionais. Dessa forma, essas respectivas instituiçóes devem possuir ou serem formalmente constituídas, ou ter estrutura básica não governamental, gestão própria, serem sem fins lucrativos e trabalho voluntário. Como exemplo dessas organizaçóes, destacam-se as criadas por iniciativas que promovem apoios assistenciais como: cooperativas, associações desportivas e as próprias fundações criadas para a manutenção e divulgação de patrimônios culturais e fundaçóes culturais, promovendo maior alcance e assistência social, entre outras.

Segundo diversos autores (Schmidt, 2017; Silva \& Aguiar, 2011; Olak \& Nascimento, 2006; Paes, 2004) coloca que o TS é composto ainda por várias entidades, dentre as quais pode-se destacar as organizaçóes sociais (em diante, OSs) e as organizaçóes da sociedade civil de interesse público (em diante, OSCIPs). As OSs são pessoas jurídicas de direito privado, sem fins lucrativos, cujo objetivo de criação é o fornecimento de serviços sociais para o público, entretanto é inerente ao governo o incentivo e a fiscalização, para que assim haja a qualificação para os termos de um acordo de gestão. Já as OSCIPs têm requisitos mais exigentes para que venham a poder obter essa significação jurídica (Jorge et al., 2021).

Contabilidad y Negocios (16) 32, 2021 / ISSN 1992-1896 
Ambos os tipos organizacionais possuem características semelhantes, como as limitações genéricas, o regime jurídico de direito privado, os objetivos próximos e a relação direta com o Estado (Araújo et al., 2018). Todavia, existem importantes distinçóes como o método que transcreve a relação, às áreas de atuação, à discricionariedade do ato de certificação, à necessidade de preexistência da entidade e presença do Poder Público no Conselho de Administração (Schmidt, 2017; Albuquerque, 2006; Paes, 2004).

\subsection{Abordagem histórica do curso de Ciências Contábeis no Brasil}

A Contabilidade e sua história é, até certo ponto, uma consequência da história da civilização, tanto em suas vicissitudes como nas mais altas manifestaçóes, sobretudo no campo da economia (Jorge et al., 2021; Silveira \& Borba, 2010; Peléias, Silva, Segreti, \& Chirotto, 2007). Exemplificando as primeiras práticas da contabilidade, Cruz et al. (2005) mostram que desde os tempos mais remotos, de forma rudimentar, o homem já adotava métodos para obter informações visando o controle de suas riquezas. Apresentavam figuras de animais expostas, em grande maioria, em pedras ou nas rochas das cavernas, que na essência poderiam ser objeto de controle.

As primeiras manifestaçóes do ensino comercial e de contabilidade no Brasil foram introduzidas a partir do século XIX, com a vinda da Família Real Portuguesa, em 1808. Nessa época, a atividade comercial brasileira resumia-se à venda dos bens produzidos ao mercado internacional. Em 1809, José da Silva Lisboa, Visconde de Cairú, promulgou o Alvará de 15 de julho, criando oficialmente o ensino de contabilidade no país, por meio das aulas de comércio denominadas de aulas práticas, que atendiam aos negócios públicos e privados, sendo usadas durante o Império (Crispim \& Miranda, 2013).
Estevão Rafael de Carvalho escreveu a obra $A$ autafisica da contabilidade comercial, em 1933, através do qual divulgou o método das partidas dobradas e propunha a elevação da contabilidade à condição de ciência (Iudícibus, Niyama, Oliveira, \& Beuren, 2020). Outro fato importante foi à fixação do regulamento das aulas de comércio, através do Decreto 456 (1996), com duração estabelecida de dois anos e exames finais abordando as disciplinas de Matemática, Geografia, Economia, Política, Direito Comercial, Prática das Principais Operações e Atos Comerciais (Soares et al., 2012). Esse diploma legal alterou a denominação das aulas práticas para aulas de comércio, que possuía disciplinas de cunho prático, voltadas às necessidades diárias dos negócios.

Com a promulgação do primeiro Código Comercial Brasileiro por meio da Lei 556, de 1850, as empresas passaram a ser obrigadas a manter a escrituração contábil, seguir uma ordem uniforme de registros contábeis e o levantamento, ao final de cada ano, de balanços gerais. Essa determinação reforça a necessidade do ensino comercial, e em 1856, surge o Instituto Comercial do Rio de Janeiro, reformando a Aula de Comércio da capital Imperial com o Decreto 1.763. A partir de 1863, esse instituto passou a oferecer a disciplina "Escrituração Mercantil", buscando qualificar seus alunos ao exercício da escrituração contábil (Iudícibus et al., 2020).

A fim de solucionar algumas falhas do Código Comercial de 1850, é promulgada a Lei 1.083 em 22 de agosto de 1860 , obrigando as empresas a publicarem e remeterem ao governo os balanços, demonstraçóes e documentos por este determinado, nos prazos e pelo modo estabelecido em seus regulamentos (Presidência da República Brasil, 1860). O governo Imperial identificou a necessidade de maior atenção à gestáo dos negócios. Isso se traduziu na promulgação do Decreto 
3.058 (1863), que reorganizou o ensino comercial do Rio de Janeiro, aumentando a duração do curso para quatro anos. Em 1890, a Escola Politécnica do Rio de Janeiro passa a oferecer a disciplina "Direito Administrativa e Contabilidade", relacionada à escrituração mercantil, associando pela primeira vez no Brasil, a Contabilidade ao Direito.

A Escola Prática de Comércio, fundada em 1902, posteriormente denominada Fundação Escola de Comércio Álvares Penteado, tornou-se uma referência no ensino comercial, ao lado da Academia de Comércio do Rio de Janeiro. Os cursos profissionalizantes, ou de Ensino técnico Comercial, foram instituídos pelo Decreto 17.329 (1926), que provou o regulamento dos estabelecimentos de ensino para oferecer um curso de formação geral de quatro anos e outro, superior, de três anos. $\mathrm{O}$ curso geral conferia o diploma de contador e o superior o título de graduando em Ciências Econômicas.

O Decreto 20.158/31, regulamentou a profissão de contador e reorganizou o ensino comercial, dividindo-os nos níveis propedêuticos, técnico e superior. O curso superior de Ciências Contábeis e Atuarias, surge por meio do Decreto Lei 7.988 (1945), com duração de quatro anos, concedendo aos seus concluintes o título de Bacharel em Ciências Contábeis. $\mathrm{Na}$ esteira da implantação do ensino superior de Contabilidade, o governo do estado de São Paulo instituiu com o Decreto-Lei 15601/46, a Faculdade de Ciências Econômicas e Administrativas - FCEA, instaladas como dependência da Universidade de São Paulo, lançando bases do primeiro núcleo de pesquisa Contábil no Brasil, com relevantes contribuiçóes para a área.

Segundo Iudícibus (2006) foi através da FCEA que o país adquiriu o primeiro núcleo efetivo de pesquisa contábil nos moldes norte-americanos. No qual os professores dedicam seus tempos ao ensino e a pes- quisa, produzindo artigos de maior conteúdo científico e escrevendo conteúdo científico e escrevendo teses acadêmicas de alta qualidade.

A Lei 1.401 (1951), desdobrou o curso de Ciências Contábeis e Atuariais, nos cursos de Ciências Contábeis e de Ciências Atuariais, instituindo diplomas distintos para ambos os cursos. Grandes mudanças ocorreram no ensino superior nos anos 60 , com reflexos nos cursos de ciências contábeis. Mudanças essas, motivadas pela Lei 4024 (1961), que fixou as Diretrizes e Bases da Educação Nacional e criou o Conselho Federal de Educação (em diante, CFE), fixando os currículos mínimos e a duração dos cursos superiores voltados à formação de profissóes regulamentadas.

O Parecer CFE 397/62, promoveu uma grande mudança no ensino de Ciências Contábeis, ao dividir o curso em ciclos de formaçáo básica e profissional. A Resolução CFE 03/92, fixou conteúdos mínimos e a duração dos cursos de graduação. Para Ciências Contábeis, além disso, fixou também normas para que as IES elaborassem os currículos definindo o perfil do profissional a ser formado.

A respeito das contribuiçóes da Resolução 03/92 para a contabilidade, Peléias et al. (2007) destacam que procura assegurar condições para o exercício profissional com competência e ética perante o meio social. E, o seu conteúdo mostra que os currículos foram elaborados para permitir o competente exercício da profissão, através do estímulo do conhecimento teórico e prático.

Atualmente, a Resolução que norteia o Currículo dos cursos de Ciências Contábeis é a CNE/CES 10/04, o qual deixa as instituiçóes livre para compor seus currículos da melhor forma que julgarem para atender as demandas da sociedade e do mercado que estáo inseridas, assim como apresenta os deveres e obrigaçóes das 
IES perante a formação dos alunos. Assim, o ensino de contabilidade no Brasil apresentou vários desafios, superados de acordo com o passar do tempo (Souza, Paixão, \& Mayer, 2020). É possível constatar que as primeiras regulamentaçóes criaram as necessidades iniciais para o ensino de contabilidade, e a demanda por profissionais melhor qualificados foi o ponto de partida para as primeiras açóes rumo à organização da profissão e criação dos órgãos de classe (Costa, Souza, Baihe, \& Albuquerque Santos Filho, 2018).

\subsection{Currículo do curso superior de Ciências Contábeis}

O termo currículo é registrado desde o século XVII e sempre esteve vinculado a um projeto de controle de ensino e aprendizagem, envolvendo uma associação entre o conceito de ordem e métodos, caracterizando-se como um instrumento facilitador da administração das instituiçôes de ensino. Cabe destacar que o currículo é um desdobramento necessário do projeto pedagógico, materializando intençôes e orientaçóes previstas no projeto em objetivo e conteúdo (Costa et al., 2018). Para Candau (2000) conceitua currículo como o conjunto do que é ensinado com o que se aprende, respeitando uma determinada ordem de progressão, no quadro de um ciclo de estudos. Completando esta afirmação Gesser e Ranghetti (2011) que o currículo traz consigo um programa de estudos ou de formação considerando em sua globalidade, coerência didática e continuidade temporal. Desta forma, pode-se afirmar que o currículo é o conjunto de itens que caracterizam a organização de uma proposta pedagógica. São os objetivos, as metas, a direção do ensino-aprendizagem, sofrendo variação do espaço, tempo, cultura e necessidades em geral do meio social que estará sendo aplicado.

Sendo assim, Candau (2000) complementa a definição feita mostrando que ele representa a introdução de uma forma particular de vida, favorecendo certas formas de conhecimento sobre outras e firma os sonhos, desejos e valores de certos grupos raciais, de classe ou gênero. No Brasil, o curso de ciências contábeis é orientado pelas diretrizes instituídas pela Resolução CNE/CES de 10 de 2004. Contudo, essas diretrizes dão autonomia às instituiçóes para comporem seus currículos da forma que julgarem melhor, a fim de suprirem as necessidades culturais, econômicas e sociais do local que estão inseridas (Conselho Nacional de Educação Brasil, 2004).

Ao estabelecer um currículo, as IES devem preocupar-se na formação dos alunos preparando-os para o mercado de trabalho e ao mesmo tempo em cidadãos que possam contribuir com seus princípios para o bem da sociedade (Souza et al., 2020). Para Althoff e Domingues (2008) às necessidades de compreender as atuais questóes socioculturais exige um novo tipo de educação que contemple as várias dimensóes do homem e da sociedade como um todo. $\mathrm{O}$ artigo $5^{\circ}$ da Resolução CNE/CES, trata da organização dos currículos e projetos pedagógicos das IES que podem ser elaborados de forma autônoma, contudo devem contemplar requisitos essenciais à formação desse profissional.

II. Conteúdos de Formação Profissional: estudos específicos atinentes às Teorias da Contabilidade, incluindo as noçóes das atividades atuariais e de quantificaçôes de informaçôes financeiras, patrimoniais, governamentais e não governamentais, de auditorias, periciais, arbitragens e controladoria, com suas aplicaçóes peculiares ao setor público e privado (Conselho Nacional de Educação Brasil, 2004, p. 6).

A resolução não especifica as disciplinas que as IES devem contemplar no seu currículo, contudo deixa claras as competências e habilidades que precisam ser desenvolvidas durante o curso de graduação para que o discente esteja apto a desempenhar a profissão, nos 
seus diversos ramos da ciência contábil. Isto está presente no artigo $4 \$ V I$ transcrito a seguir:

suas responsabilidades com o expressivo domínio das funçôes contábeis, incluindo noçôes de atividades atuariais e de quantificaçôes de informaçóes patrimoniais e governamentais, que viabilizem aos agentes econômicos e aos administradores de qualquer segmento produtivo ou institucional o pleno cumprimento de seus encargos quanto ao gerenciamento, aos controles e à prestação de contas de sua gestão perante à sociedade, gerando também informações para tomada de decisão, organização de atitudes e construçấo de valores orientados para a cidadania.

As IES devem buscar adequação às disciplinas que serão abordadas no sentido de contemplarem a carga horária ou até que a mesma disciplina esteja presente no currículo mais de uma vez, dando continuidade ao que já foi estudado numa etapa anterior (Araújo et al., 2018). Nesse contexto se insere a contabilidade aplicada ao TS, que traz uma demanda vasta de informaçóes relevantes, as quais devem ser objeto de estudo dos graduandos de forma a suprir as necessidades dos profissionais que se tornarão bacharéis e atuarão nesse ramo. Sobre essa importância da abordagem pertinente do TS nos currículos, a Resolução CNE/CES de 10 de dezembro de 2004, em seu artigo $3 \$$ I e II, diz que:

O curso de graduação em Ciências Contábeis deve ensejar condiçóes para que o futuro contabilista seja capacitado a:

I. compreender as questôes científicas, técnicas, sociais, econômicas e financeiras, em âmbito nacional e internacional e nos diferentes modelos de organização;

II. apresentar pleno domínio das responsabilidades funcionais envolvendo apuraçôes, auditorias, perícias, arbitragens, noções de atividades atuariais e de quantificaçóes de informaçóes financeiras, patrimoniais e governamentais, com a plena utilização de inovaçóes tecnológicas.

Gesser e Ranghetti (2011) destacam que não há consenso para o significado da palavra currículo, mas ressaltam que:

Diante dos desafios que o mundo atual nos apresenta, diante da nossa responsabilidade de formar profissionais para atuar frente às informaçôes e mudanças que vêm ocorrendo freneticamente, urge a necessidade de se desenvolver currículos para a formação de profissionais no ensino superior aptos para assumir novos papéis (p. 3).

Essa necessidade de adequação diz respeito também ao estudo TS como disciplina nos cursos de ciências contábeis uma vez que diz respeito à sociedade como um todo diante da ferramenta de gestão que a mesma representa na administração das entidades sem fins lucrativos.

\section{Metodologia}

A presente pesquisa, quanto aos fins a que se destina, é definida como exploratória, por ter como objetivo, segundo Gil (2002), proporcionar maior familiaridade com o assunto, visando torná-lo mais explícito e possibilitando a construção de hipóteses. Quanto aos meios, classifica-se como pesquisa bibliográfica, buscando desenvolver um estudo sistematizado com base em material publicado em livros, jornais, revistas" (Vergara, 2006; Araújo et al. 2019), visando apresentar o panorama do ensino de Ciências Contábeis do TS no curso de Ciências Contábeis frente ao seu destaque e crescimento.

Para cumprir com o objetivo do trabalho se investigou de que maneira as IES vêm contemplando disciplinas ligadas ao TS (obrigatória ou eletiva) e qual a relevância delas para a formação do graduando que pretende atuar na área, carga horária, oferta de vagas e se as mesmas atendem às necessidades do MEC, diante a Resolução 4 de 2006, bem como às necessidades do 
mercado. A escolha pela universidade pública e de caráter presencial se deu por estas terem obrigatoriamente atender a Resolução 4 de 2006, de possuírem disciplinas que tratam para TS.

Para tanto, foi realizado como primeiro passo a coleta de dados que foi realizado o acompanhamento das informaçóes no MEC desde o ano de 2017 a 2020, utilizados neste trabalho, para a análise curricular das IES de graduação e bacharelado em ciências contábeis, nos quais foram observadas as seguintes categorias:

Tabela 1. Categorias analisadas nas IES

\begin{tabular}{|c|l|}
\hline item & \multicolumn{1}{|c|}{ Categorias } \\
\hline 1 & $\begin{array}{l}\text { Perfil das IES no que concerne ao currículo do curso } \\
\text { de graduação em ciências contábeis }\end{array}$ \\
2 & $\begin{array}{l}\text { A distribuição das disciplinas e a respectiva carga } \\
\text { horária }\end{array}$ \\
3 & $\begin{array}{l}\text { Disciplinas relacionadas ao TS; } \\
\text { Disciplinas que compóem o currículo das IES pesqui- } \\
\text { sadas voltadas ao TS }\end{array}$ \\
\hline
\end{tabular}

Fonte: Elaborado pelos autores.

A tabela 1 marca o roteiro de análise das informaçóes dispostas no Plano Pedagógico do curso de ciências contábeis de cada IES pesquisadas, os quais deram sustentação na identificação das disciplinas voltadas ao TS, das ementas para reflexão das possíveis melhorias que podem ser inferidas da prática contábil nas instituições públicas e da proposta de formação curricular disponibilizados nos sites das IES. Por sua vez, foram selecionadas por meio do site oficial do Ministério da Educação (em diante, MEC), no intuito de que as informações estejam respaldadas por órgão oficial e regulador das mesmas. $\mathrm{Na}$ fase de categorização foi estabelecido a forma de categorização dos aspectos pesquisados em cada elemento de análise, como a frequência dos achados e por qual dos sujeitos da pesquisa. A tabela 2 apresenta a definição da amostra.
Tabela 2. Definiçáo da amostra

\begin{tabular}{|c|l|c|}
\hline item & \multicolumn{1}{|c|}{ Analisado } & Quantidade \\
\hline 1 & $\begin{array}{l}\text { Total de IES que possuem o curso } \\
\text { de C.C. }\end{array}$ & 77 \\
2 & $\begin{array}{l}\text { Estados que possuem o curso de } \\
\text { C.C. } \\
3\end{array}$ & $\begin{array}{l}\text { IES que possuem disciplinas relacio- } \\
\text { nadas a TS }\end{array}$ \\
$\begin{array}{l}\text { IES que apresentam disciplinas } \\
\text { específicas de TS } \\
\text { Total de disciplinas TS (4+5) }\end{array}$ & 46 \\
\hline
\end{tabular}

Fonte: Elaboraçâo própria dos autores, dados da pesquisa (2020).

A tabela 2 apresenta a identificação de 77 instituiçóes públicas que ofertavam o curso de Ciências Contábeis, distribuídas em 25 estados, bem como seus respectivos currículos, sendo que 46 possuíam disciplinas relacionadas ao TS em sua matriz curricular, 16 disciplinas específicas de TS, gerando um total de disciplinas encontradas foi 62 evidenciadas. A tabela 3 apresenta a lista de universidades analisadas na pesquisa

Embora tenham sido encontrados todos os currículos das 77 IES, não foi possível identificar no currículo, disciplinas com nomes genéricos como "tópicos especiais" que, embora pudessem se referir ao TS, foram desconsideradas quando não encontrada a respectiva ementa. Tais instituiçóes foram pesquisadas obedecendo aos critérios tais como, (I) ser a IES; (II) ofertar o curso de Ciências Contábeis na modalidade presencial; (III) constar entre as IES presentes na lista disponibilizada pelo MEC e (IV) a IES está em atividade. A partir destas informaçóes classificadas se efetuou uma análise descritiva dos dados encontrados e tabulados por meio do software SPSS. Seguindo para tratamento dos dados que compreendeu a contagem e a identificação das ementas de cada um dos aspectos pesquisados, e a aferição da sua frequência em cada categoria de elementos de análise. 
Tabela 3. Universidades analisadas por regiáo

\begin{tabular}{|c|c|c|c|c|}
\hline No & REGIÃO & ESTADO & UNIVERSIDADE & SIGLA \\
\hline 1 & SUDESTE & Espírito Santo & Universidade Federal do Espírito Santo & UFES \\
\hline 2 & SUDESTE & Minas Gerais & Universidade Federal de Juiz de Fora & UFJF \\
\hline 3 & SUDESTE & Minas Gerais & Universidade Federal de Minas Gerais & UFMG \\
\hline 4 & SUDESTE & Minas Gerais & Universidade Federal de São João del-Rei & UFSJ \\
\hline 5 & SUDESTE & Minas Gerais & Universidade Federal de Uberlândia & UFU \\
\hline 6 & SUDESTE & Minas Gerais & Universidade Federal de Viçosa & UFV \\
\hline 7 & SUDESTE & Minas Gerais & Universidade Federal dos Vales do Jequitinhonha e Mucuri & UFVJM \\
\hline 8 & SUDESTE & São Paulo & Universidade Federal de São Paulo & UNIFESP \\
\hline 9 & SUDESTE & São Paulo & Universidade Estadual de São Paulo & USP \\
\hline 10 & SUDESTE & São Paulo & Cenro Universitário Municipal de Franca & Uni-FACEF \\
\hline 11 & SUDESTE & Rio de Janeiro & Universidade Federal do Rio de Janeiro & UFRJ \\
\hline 12 & SUDESTE & Rio de Janeiro & Universidade Federal Fluminense & UFF \\
\hline 13 & SUDESTE & Rio de Janeiro & Universidade Federal Rural do Rio de Janeiro & UFRRJ \\
\hline 14 & CENTRO OESTE & Distrito Federal & Universidade de Brasília & UnB \\
\hline 15 & CENTRO OESTE & Goiás & Universidade Federal de Goiás & UFG \\
\hline 16 & CENTRO OESTE & Goiás & Universidade do Rio Verde & UniRV \\
\hline 17 & CENTRO OESTE & Goiás & Faculdade de Filosofia e Ciências Humanas de Goiatuba & FAFICH \\
\hline 18 & CENTRO OESTE & Goiás & Faculdade de Educação e Ciência Humanas de Anicuns & FECHA \\
\hline 19 & CENTRO OESTE & Mato Grosso & Universidade Federal de Mato Grosso & UFMT \\
\hline 20 & CENTRO OESTE & Mato Grosso & Universidade Estadual de Mato Grosso & UEMT \\
\hline 21 & CENTRO OESTE & Mato Grosso do Sul & Universidade Federal de Mato Grosso do Sul & UFMS \\
\hline 22 & CENTRO OESTE & Mato Grosso do Sul & Universidade Federal da Grande Dourados & UFGD \\
\hline 23 & CENTRO OESTE & Mato Grosso do Sul & Universidade Estadual de Mato Grosso do Sul & UEMS \\
\hline 24 & NORTE & Amazonas & Universidade Federal do Amazonas & UFAM \\
\hline 25 & NORTE & Amazonas & Universidade Federal Rural do Amazonas & UFRA \\
\hline 26 & NORTE & Amazonas & Universidade Estadual do Amazonas & UEA \\
\hline 27 & NORTE & Pará & Universidade Federal do Pará & UFPA \\
\hline 28 & NORTE & Pará & Universidade Federal do Sul e Sudeste do Pará & UNIFESSPA \\
\hline 29 & NORTE & Rondônia & Universidade Federal de Rondônia & UNIR \\
\hline 30 & NORTE & Roraima & Universidade Federal de Roraima & UFRR \\
\hline 31 & NORTE & Roraima & Universidade Estadual de Roraima & UERR \\
\hline
\end{tabular}




\begin{tabular}{|c|c|c|c|c|}
\hline No & REGIÃO & ESTADO & UNIVERSIDADE & SIGLA \\
\hline 32 & NORTE & Tocantins & Universidade Federal do Tocantins & UFT \\
\hline 33 & NORTE & Tocantins & Universidade Estadual do Tocantins & UNITINS \\
\hline 34 & SUL & Paraná & Universidade Tecnológica Federal do Paraná & UTFPR \\
\hline 35 & SUL & Paraná & Instituto Federal de Educação, Ciência e Tecnologia do Paraná & IFPR \\
\hline 36 & SUL & Paraná & Universidade Federal do Paraná & UFPR \\
\hline 37 & SUL & Paraná & Universidade Estadual do Centro-Oeste & UNICENTRO \\
\hline 38 & SUL & Paraná & Universidade Estadual do Oeste do Paraná & UNIOESTE \\
\hline 39 & SUL & Paraná & Universidade Estadual de Ponta Grossa & UEPG \\
\hline 40 & SUL & Paraná & Universidade Estadual do Norte do Paraná & UENP \\
\hline 41 & SUL & Paraná & Universidade Estadual do Paraná & UNESPAR \\
\hline 42 & SUL & Rio Grande do Sul & Universidade Federal de Santa Maria & UFSM \\
\hline 43 & SUL & Rio Grande do Sul & Fundação Universidade Federal do Rio Grande & FURG \\
\hline 44 & SUL & Rio Grande do Sul & Universidade Federal do Rio Grande do Sul & UFRGS \\
\hline 45 & SUL & Santa Catarina & Universidade Federal de Santa Catarina & UFSC \\
\hline 46 & SUL & Santa Catarina & Universidade Estadual de Santa Catarina & UDESC \\
\hline 47 & SUL & Santa Catarina & Universidade Regional de Blumenau & FURB \\
\hline 48 & SUL & Santa Catarina & Centro Universitário Municipal de São José & USJ \\
\hline 49 & NORDESTE & Alagoas & Universidade Federal de Alagoas & UFAL \\
\hline 50 & NORDESTE & Alagoas & Universidade Estadual de Alagoas & UNEAL \\
\hline 51 & NORDESTE & Bahia & Universidade Federal da Bahia & UFBA \\
\hline 52 & NORDESTE & Bahia & Universidade Estadual de Feira de Santana & UEFS \\
\hline 53 & NORDESTE & Bahia & Universidade do Estado da Bahia & UNEB \\
\hline 54 & NORDESTE & Ceará & Universidade Federal do Ceará & UFC \\
\hline 55 & NORDESTE & Maranhão & Universidade Federal do Maranhão & UFMA \\
\hline 56 & NORDESTE & Paraíba & Universidade Federal da Paraíba & UFPB \\
\hline 57 & NORDESTE & Paraíba & Universidade Federal de Campina Grande & UFCG \\
\hline 58 & NORDESTE & Pernambuco & Universidade Federal de Pernambuco & UFPE \\
\hline 59 & NORDESTE & Piauí & Universidade Federal do Piauí & UFPI \\
\hline 60 & NORDESTE & Rio Grande do Norte & Universidade Federal do Rio Grande do Norte & UFRN \\
\hline 61 & NORDESTE & Rio Grande do Norte & Universidade Federal Rural do Semi-Árido & UFERSA \\
\hline 62 & NORDESTE & Sergipe & Universidade Federal de Sergipe & UFS \\
\hline
\end{tabular}

Fonte: Elaborado pelos autores. 
$\mathrm{O}$ estudo foi realizado tendo em vista o aumento das entidades do TS e pelos impactos decorrentes de suas atividades na sociedade e os pressupostos existentes pela demanda por profissionais cada vez mais qualificados (Instituto de Pesquisa de Economia Aplicada [IPEA], 2020, Iudícibus, et al., 2020). Além disso, no trabalho de Silveira \& Borba (2010) vem discutindo a existência de poucos profissionais nesta área, assim como evidencia problemas na prestação de contas e na confecção de demonstrativos contábeis pela oferta de disciplinas dentro dos cursos de ciências contábeis, corroborando com estudo de Quinn \& Hiebl (2018).

\section{Análise dos resultados}

Para obtenção dos dados, foram pesquisadas as páginas de cada IES, suas matrizes curriculares e respectivos ementários. Ao analisar proporcionalmente o número de instituiçóes que ofertam disciplinas relacionadas ao TS e o número total de instituições que oferecem o curso de Ciências Contábeis, presentes na tabela 4 .

Tabela 4. Distribuiçáo de IES com disciplina do TS por regiáo

\begin{tabular}{|l|c|c|c|}
\hline \multicolumn{1}{|c|}{ Regiáo } & IES & IES com disciplinas do TS & $\%$ \\
\hline Norte & 10 & 7 & $70 \%$ \\
Nordeste & 22 & 15 & $68,18 \%$ \\
Sul & 17 & 10 & $58,82 \%$ \\
Sudeste & 17 & 10 & $58,82 \%$ \\
Centro-Oeste & 11 & 4 & $36,36 \%$ \\
\hline Total & 77 & 46 & $59,74 \%$ \\
\hline
\end{tabular}

Fonte: Elaboração própria dos autores, dados da pesquisa (2020).

A tabela 4 indica que cerca de 59,74\% das IES da amostra possuem disciplinas relacionadas ao TS em suas matrizes curriculares. A região que mais oferta proporcionalmente foi a Norte com $70 \%$ de suas IES. Conforme indicado na tabela 4, 46 IES $(59,4 \%)$ ofertam disciplinas relacionadas ao TS.
Tabela 5. Número de disciplinas ofertadas por cada IES/ Relaçáo quantidade de disciplinas voltadas ao TS $\mathrm{x}$ IES pesquisadas

\begin{tabular}{|l|c|c|c|}
\hline $\begin{array}{c}\text { OFERTA DISCI- } \\
\text { PLINA }\end{array}$ & $\begin{array}{c}\text { NÚMERO } \\
\text { DE IES }\end{array}$ & $\begin{array}{c}\text { TOTAL DE } \\
\text { DISCIPLINAS }\end{array}$ & $\begin{array}{c}\text { PERCEN- } \\
\text { TUAL }\end{array}$ \\
\hline $\begin{array}{l}\text { Nenhuma disci- } \\
\text { plina }\end{array}$ & 31 & 0 & $40,26 \%$ \\
1 Disciplina & 31 & 31 & $40,26 \%$ \\
2 Disciplinas & 14 & 28 & $18,18 \%$ \\
3 Disciplinas & 1 & 3 & $1,30 \%$ \\
Não informa & 0 & 0 & $0 \%$ \\
\hline Total & 77 & 62 & $100 \%$ \\
\hline
\end{tabular}

Fonte: Elaboração própria dos autores, dados da pesquisa.

Na tabela 5 foi identificada a relaçáo de quantidade de disciplinas voltadas ao TS para cada IES pesquisada. Com resultados expostos na tabela 4. Foi observado que há uma grande variação entre a carga horária das IES que oferecem disciplinas ligadas ao TS, essa variação vai de 30 até 90 horas, sendo que metade das disciplinas encontradas foi de 60 horas. Tais informaçóes estão dispostas na tabela 6 .

Tabela 6. Quantidade de disciplinas por carga horária nas IES do Brasil

\begin{tabular}{|c|c|c|}
\hline $\mathrm{CH}$ & DISCIPLINAS & $\%$ \\
\hline $\mathbf{6 0}$ & 31 & $50,00 \%$ \\
$\mathbf{6 8}$ & 8 & $12,90 \%$ \\
30 & 7 & $11,29 \%$ \\
72 & 4 & $6,45 \%$ \\
36 & 3 & $4,84 \%$ \\
40 & 3 & $4,84 \%$ \\
$\mathbf{6 4}$ & 2 & $3,23 \%$ \\
32 & 1 & $1,61 \%$ \\
34 & 1 & $1,61 \%$ \\
51 & 1 & $1,61 \%$ \\
$\mathbf{9 0}$ & 1 & $1,61 \%$ \\
Náo informa & 0 & $0 \%$ \\
\hline Total & 62 & $100 \%$ \\
\hline
\end{tabular}

Fonte: Elaboração própria dos autores, dados da pesquisa. 
Dados as informaçóes por carga horária nas IES, segue a apresentação da distribuição da carga horária de acordo com a região, conforme tabela 7 .

Tabela 7. Carga horária média por região

\begin{tabular}{|l|c|}
\hline \multicolumn{1}{|c|}{ Região } & CH \\
\hline Nordeste & 61,30 \\
Centro-Oeste & 58,40 \\
Sul & 55,29 \\
Norte & 53,30 \\
Sudeste & 50,14 \\
\hline Brasil & 55,89 \\
\hline
\end{tabular}

Fonte: Elaboração própria dos autores, dados da pesquisa.

A tabela 7 aponta que a carga-horária média nas regióes do Brasil varia de 50 horas a 61 horas. Sendo o Nordeste a região que oferta a maior carga horária média. Quanto ao semestre de oferta das disciplinas, mais de $70 \%$ é oferecido como seletiva, sem um período fixo. As informaçôes estão expostas na tabela 8

Tabela 8. Disciplinas obrigatórias $\mathrm{x}$ eletivas

\begin{tabular}{|l|c|c|}
\hline \multicolumn{1}{|c|}{ Obrigatórias } & 18 & $29,03 \%$ \\
\hline Eletivas & 44 & $70,97 \%$ \\
\hline Total & 62 & $100 \%$ \\
\hline
\end{tabular}

Fonte: Elaboração própria dos autores, dados da pesquisa.

Dados os resultados, observa-se que $70,97 \%$ das disciplinas ofertadas são eletivas. Note que estes dados revelam que a maioria das IES pode não está dando a devida importância para disciplina de TS. Ao avaliar a oferta da disciplina nos semestres de acordo com a análise do plano pedagógico do curso, de acordo com a tabela 9 .

A tabela 9 demonstra que a maioria das vezes entre o quarto e quinto semestre do curso. Cabe ressaltar que as disciplinas que são ofertadas de forma anual, não foram consideradas na tabela 9 efetuando um panorama das disciplinas obrigatórias e optativas (eletivas) na figura 1 .

Tabela 9. Semestre em que as disciplinas relacionadas ao TS são ofertadas em IES em São Paulo

\begin{tabular}{|l|c|c|c|c|c|c|c|}
\hline Semestre & $3^{\circ}$ & $4^{\circ}$ & $5^{\circ}$ & $6^{\circ}$ & $7^{\circ}$ & $8^{\circ}$ & 9 \\
\hline Quantidade & 1 & 3 & 3 & 2 & 2 & 1 & 1 \\
\hline
\end{tabular}

Fonte: Elaboraçấo própria dos autores, dados da pesquisa (2020).

Figura 1. Oferta de disciplinas total; de optativas e de obrigatórias por região
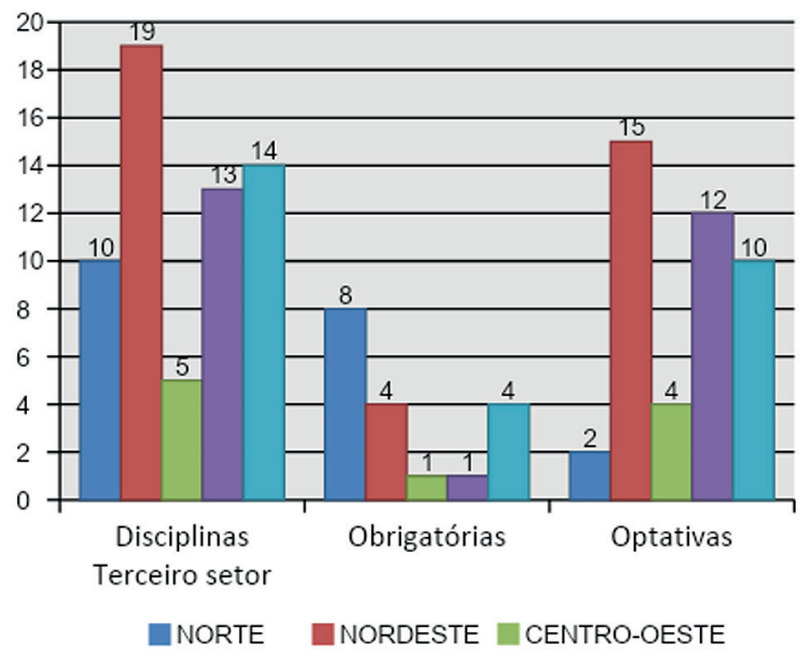

SUDESTE — SUL

$\mathrm{Na}$ figura 1 consta um panorama geral de oferta de disciplinas no Brasil, se dividindo em seçóes, sendo a primeira o total de disciplinas relacionadas ao TS em cada regiáo, a segunda destaca as obrigatórias e a terceira as optativas. A região com maior número de disciplinas totais e optativas é o Nordeste, ofertando 19 e 15 disciplinas respectivamente. Enquanto a com mais obrigatórias é o Norte (8). Avaliando estas informaçóes na tabela 10 . 
Tabela 10. Resultados encontrados

\begin{tabular}{|l|c|c|}
\hline \multicolumn{1}{|c|}{ Destaques } & Localidade & Resultado \\
\hline Regiáo que mais oferta & Nordeste & 19 \\
Regiáo com maior CH média & Nordeste & 61,30 \\
Regiáo com maior CH total & Nordeste & 1.164 \\
Regiáo com mais obrigatórias & Norte & 8 \\
Estado que mais oferta & MG e BA & 7 \\
Estado com maior CH total & BA & 436 \\
Estado com maior CH média & MS & 70 \\
Estado com mais obrigatórias & PA & 3 \\
IES que mais oferta & UNIFESP & 3 \\
IES com maior CH total & UNIFESP & 150 \\
IES com maior CH média & UFPA & 90 \\
IES com mais obrigatórias & UNIR & 2 \\
\hline
\end{tabular}

Fonte: Elaboração própria dos autores, base nos dados da pesquisa.

$\mathrm{Na}$ tabela 10 constam os melhores resultados. O maior destaque dentre as regióes vai para o Nordeste que de acordo com a pesquisa, é a que oferta maior número de disciplinas (19), bem como maior carga horária total (1.164) e média $(61,3)$. Dentre os estados é a Bahia que se destaca em oferta de disciplinas (7) e maior $\mathrm{CH}$ total (436), sendo o estado com maior CH média o MS (70). Já no que se refere às IES, a UNIFESP foi a que mais se destacou, ofertando o maior número de disciplinas (3), bem como maior $\mathrm{CH}$ total (150), enquanto a UNIR foi a que ofertou maior número de disciplinas obrigatórias.

\section{Discussáo dos resultados}

A perspectiva de que o TS venha a suprir parte dos problemas da sociedade perante a ineficiência do Estado (Silveira \& Borba, 2010). Observa-se que os estudos no TS não acompanham a quantidade de organizaçóes que foram criadas ao longo dos anos. Da mesma forma, que o TS apresenta grande potencial de desenvolvimento social, mas necessita ainda de forte amadurecimento em termos de profissionalização revelados pelos resultados do estudo e corroborando com Jorge (2020), Araújo et al. (2019), Zittei et al. (2016), Portulhak et al. (2015), e Soares et al. (2012).

Da mesma forma, quem está na linha de frente da entidade precisa entender o que é necessário para o funcionamento da mesma, assim como compreender a contabilidade aplicada a entidades do TS (Romoaldo \& Santos, 2020). Por mais que o gestor ou qualquer outro funcionário não domine a temática, se faz necessário conhecer suas particularidades. Para tanto, a contabilidade descortina informaçóes tornando-se fonte inesgotável de informaçóes que demonstram a situaçáo das entidades num determinado momento (Araújo, et al., 2018). Cabe ressaltar que a contabilidade para o TS tem sua importância como as demais áreas de estudo da contabilidade e por meio dos procedimentos contábeis, de controle, das normas e o gerenciamento contábil (Mañas \& Medeiros, 2012).

Evidências complementares demonstram que o processo de mudança no plano pedagógico do curso com a inclusão de disciplinas TS ou a discussão desta na ementa de outra disciplina, faz com que os discentes consigam ter conhecimento sobre este tipo de instituições enquadradas como TS. Para tanto, a transparência na Contabilidade resulta da adequada evidenciação contábil que é desenvolvida por meio da prestação de contas das entidades para a sociedade (Olak \& Nascimento, 2010). Outrossim, os autores trazem em questão as perspectivas analisadas em termos de evidenciação, relevância à informaçóes fidedignas e completas que possibilitam o usuário a visualizar toda a estrutura patrimonial da instituição como base de apoio à decisão. Esses resultados corroboram os estudos anteriores sobre a educação de TS na graduação de ciências contábeis na implementação de práticas de contabilidade nas organizaçôes, segundo Jorge et al. (2021), Araújo et al. (2019), Silveira e Borba (2010), e Peléias et al. (2007). 


\section{Conclusáo}

O trabalho teve como objetivo apresentar o panorama do ensino de Contabilidade Aplicada ao TS e utilizando as disciplinas ofertadas no curso superior nas IES públicas no Brasil como proxy, constatou que a oferta não é satisfatória. A IES que mais oferece disciplinas e que tem maior carga horária é a UNIFESP. A região que se destaca é o Nordeste e os Estados que mais oferecem disciplinas são: Bahia e Minas Gerais. A maioria das IES (70,9\%) oferece a disciplina como facultativa, o que indica a pouca atenção dada a essa temática. Destaca-se que o curso de Ciências Contábeis tem suas disciplinas mais direcionadas para o ensino da Contabilidade empresarial e existe pouca oferta de disciplinas orientadas para o TS, o que representa um grande desafio para melhoria dessas instituições, uma vez que é a Contabilidade, responsável pela elaboração das suas demonstrações e prestação de contas. Esses resultados contribuem aos gestores e professores do curso de Ciências Contábeis para que se criem mais disciplinas e interdisciplinaridades com o TS e consequentemente crie melhorias no processo de ensino em Contabilidade no Brasil.

A limitação da pesquisa se deu pela coleta de dados por meio de documentos, instrumentos presentes no portal do MEC e das IES sujeitas à pesquisa, que não permitem captar toda a complexidade do problema de educação em TS. A análise dos resultados advindos deste trabalho depende da reflexão empírica rigorosa do pesquisador. Para reduzir esse viés, futuras pesquisas podem aplicar o estudo a qualificação e prática dos docentes na área de TS, assim como a influência da oferta da disciplina de acordo o interesse dos discente, criando novos construtos de pesquisa, triangulação de múltiplas fontes e validação das interpretaçôes.

\section{Referências}

Albuquerque, A. C. C. (2006). Terceiro setor: história e gestão de organizaçôes. São Paulo: Summus Editorial.

Althoff, N. S., \& Domingues, M. J. C. D. S. (2008). Práticas interdisciplinares nos cursos de graduação em Ciências Contábeis: mito ou realidade. In Congresso da Associação Nacional dos Progradas de Pós-Graduação em Contabilidade (Vol. 2) (pp. 1-16). Salvador: ANPCONT.

Araújo, J C O., Costa, J. R. S., Costa, R. N. V. Da, \& Furtado, V. G. S. (2019). Controlar para caminhar: um olhar sobre a utilização do controle Contábil e dos sistemas de controle em associaçóes. Revista Científica Multidisciplinar Núcleo do Conhecimento, 4(4), 121-145. https:// doi.org/10.32749/nucleodoconhecimento.com.br/ contabilidade/controlar-para-caminhar

Araújo, J. C. O., Pires, J. O. M., \& Farias Filho, M. C. (2018). Ganhos competitivos e gestão contábil coletiva: o caso das cooperativas de materiais recicláveis do estado do Pará (Vol. 1). Olinda: Editora Livro Rápido.

Araújo, T. S., Leal, E. A., \& Lourenço, R. F. (2021). Expectativas e satisfação dos discentes sobre os saberes e competências requeridas dos docentes na área de ciências contábeis. Revista Ambiente Contábil, 13(1), 324-342. https://doi.org/10.21680/21769036.2021v13n1ID20179

Assembleia Legislativa do Estado de São Paulo. (1946, 26 de janeiro). Dispóe sobre a instalação da Faculdade de Ciências Econômicas e Administrativas da Universidade de São Paulo [Decreto-Lei No 15.601]. Recuperado de https://www.lexml.gov.br/urn/urn:lex:br;sao. paulo:estadual:decreto.lei:1946-01-26;15601 [Consulta: 15 de setembro de 2017].

Brasil. (1962). Fixa os conteúdos minimos e duração para o curso de ciências contábeis [Parecer No 397/62]. Recuperado de https://www.maxwell.vrac.puc-rio. br/9040/9040_2.PDF [Consulta: 15 de setembro de 2017]. 
Brasil. (1992). Retifica o parecer No $397 / 62$ e fixa os conteúdos minimos e duração de 4 anos para o curso de ciências contábeis [Parecer No 03/92]. Recuperado de http://www.dominiopublico.gov.br/download/texto/ cd000931.pdf [Consulta: 15 de setembro de 2017].

Câmara dos Deputados Brasil. (1863, 11 de março). Da novos estatutos ao instituto comercial do Rio de Janeiro [Decreto No 3.058]. Recuperado de https://www2. camara.leg.br/legin/fed/decret/1824-1899/decreto3058-11-marco-1863-554997-publicacaooriginal74014-pe.html [Consulta: 15 de setembro de 2017].

Câmara dos Deputados Brasil. (1926, 28 de maio). Approva, o regulamento para os estabelecimentos de ensino technico commercial reconhecidos officialmente pelo Governo Federal [Decreto No 17.329]. Recuperado de https:// www2.camara.leg.br/legin/fed/decret/1920-1929/ decreto-17329-28-maio-1926-514068-republicacao88142-pe.html\#:- :text=Approva\%2C\%20o\%20regulamento\%20para $\% 20$ os,de\%20acc\%C3\%B4rdo\%20 c o m \% 20 o \% 20 n. \& t ex t $=48 \% 20$ d a $\% 20$ Constitui\%C3\%A7\%C3\%A3o\%20Federal\%20e\%20 tendo $\% 20 \mathrm{em} \% 20$ vista $\% 20$ os $\% 20$ decretos $\% 20$ legislativos\%20ns [Consulta: 15 de setembro de 2017].

Câmara dos Deputados Brasil. (1931, 30 de junho). Organiza o ensino comercial, regulamenta a profissáo de contador e dá outras providências [Decreto $\mathrm{N}^{\circ} 20.158$ ]. Recuperado de https:/www2.camara.leg.br/legin/ fed/decret/1930-1939/decreto-20158-30-junho1931-536778-republicacao-81246-pe.html [Consulta: 15 de setembro de 2017].

Câmara dos Deputados Brasil. (1945, 22 de setembro). Dispóe sôbre o ensino superior de ciências econômicas e de ciências contábeis e atuariais [Decreto Lei No 7.988]. Recuperado de https://www2.camara.leg.br/legin/ fed/declei/1940-1949/decreto-lei-7988-22-setembro1945-417334-norma-pe.html [Consulta: 15 de setembro de 2017].

Candau, V. M. (2000). O currículo entre o relativismo e o universalismo: dialogando com Jean-Claude Forquin.
Educação \& Sociedade, 21(73), 79-83. https://doi. org/10.1590/S0101-73302000000400006

Conselho Nacional de Educação Brasil. (2004, 16 de dezembro). Institui as Diretrizes Curriculares Nacionais para o Curso de Graduaçấo em Ciências Contábeis, bacharelado, e dá outras providências [Resolução CNE/ CES No 10/2014]. Recuperado de http://portal.mec. gov.br/cne/arquivos/pdf/rces010_04.pdf [Consulta: 15 de setembro de 2017].

Conselho Nacional de Educação. (2005, 13 de julho). Diretrizes Curriculares Nacionais do Curso de Graduação em Administração [Resolução $\mathrm{N}^{\circ}$ 4]. Recuperado de http://portal.mec.gov.br/cne/arquivos/pdf/ rces004_05.pdf [Consulta: 15 de setembro de 2017].

Costa, F. B., Souza, F. G. de, Baihe, M. J. A., \& Albuquerque Santos Filho, S. de. (2018). Perfil do profissional contábil do setor público: uma análise das capitais brasileiras e distrito federal. Revista de Contabilidade da UFBA, 12(1), 74-92. https://doi.org/10.9771/rcufba.v12i1.23253

Crispim, G., \& Miranda, L. C. (2013). O ensino da contabilidade no curso de administração de empresa: a percepção do corpo discente das disciplinas de contabilidade na sua formação acadêmica. ASAA-Advances in Scientific and Applied Accounting, 5(1), 131-155. https://doi.org/10.14392/ASAA/2012050106

Cruz, F. B., Lima Trindade, L. de, Silva Figueró, L. R. da, Denardin, M., Friedrich, R., \& Brondani, G. (2005). A informação contábil em prol do bem estar social. Revista Eletrônica de Contabilidade, 2(3), 219-229.

Falconer, A. P. (1999). A promessa do terceiro setor. São Paulo: Centro de Estudos em Administraçáo do Terceiro Setor. Universidade de São Paulo.

Gesser, V., \& Ranghetti, D. S. (2011). O currículo no ensino superior: princípios epistemológicos para um design contemporâneo. Revista e-curriculum, 7(2), 1-23.

Gil, A. C. (2002). Como elaborar projetos de pesquisa (Vol. 4). São Paulo: Atlas. 
Gohn, M. G. (2008). Teorias dos movimentos sociais: Paradigmas clássicos e contemporâneos. São Paulo: Ediçôes Loyola.

Goretzki, L., Strauss, E., \& Weber, J. (2013). An institutional perspective on the changes in management accountants' professional role. Management Accounting Research, 24(1), 41-63. https://doi.org/10.1016/j. mar.2012.11.002

Governo do Estado De Goiás. (1980, 16 de janeiro). Disciplina o uso dos veículos pertencentes ao Serviço Público do Estado [Decreto No 1.763]. Recuperado de https:// legisla.casacivil.go.gov.br/pesquisa_legislacao/66763/ decreto-1763 Acessado em jun. 2019

Healy, P. N., \& Palepu, K. G. (2001). Information asymmetry, corporate disclosure, and the capital markets: A review of the empirical disclosure literature. Journal of Accounting \& Economic, 31, 405-440. https://doi. org/10.1016/S0165-4101(01)00018-0

Hudson, M. (2002). Administrando organizaçôes do terceiro setor: o desafio de administrar sem receira. São Paulo: Pearson Education.

Innocenti, R. M., Lunkes, R. J., \& Gasparetto, V. (2021). Institucionalização de regras e rotinas da contabilidade gerencial em uma fundação privada educacional catarinense: abordagem institucional do terceiro setor brasileiro. Revista Ambiente Contábil-Universidade Federal do Rio Grande do Norte, 13(1), 302-323. https://doi.org/10.21680/2176-9036.2021v13n1ID 19648

Instituto Brasileiro de Geografia e Estatística (IBGE). (2017). Censo 2010. Recuperado de https://censo2010.ibge.gov.br/noticias-censo? id=1 \&idnoticia= 2278\&view=noticia \&wvdpforce=1 [Consulta: 9 de outubro de 2017].

Instituto Brasileiro de Geografia e Estatística (IBGE). (2020). Produto Interno Bruto - PIB e terceiro setor. online. Recuperado de https://www.ibge.gov.br/explica/pib.php [Consulta: 15 de setembro de 2017].
Instituto de Pesquisa de Economia Aplicada (IPEA). (2020). Mapa das organizaçóes da sociedade civil. Recuperado de https://mapaosc.ipea.gov.br/base-dados. html [Consulta: 15 de setembro de 2017].

Iudícibus, S. (2006). Teoria da contabilidade. Sáo Paulo: Atlas.

Iudícibus, S. D. (2010). Contabilidade introdutória. São Paulo: Atlas.

Iudícibus, S., Niyama, J. K., Oliveira, V. R. F. de, \& Beuren, I. M. (2020). Reflexôes sobre as bases filosóficas dos princípios contábeis. Revista Contemporânea de Contabilidade, 17(42), 158-173. https:/doi. org/10.5007/2175-8069.2020v17n42p158

Jorge, F. D. S. (2020). Fatores determinantes da accountability no terceiro setor (Dissertação de mestrado, Faculdade de Ciências Econômicas, Universidade Federal do Rio Grande do Sul. Porto Alegre, Brasil).

Jorge, F. S., Souza, Â. R. L. D., \& Vendruscolo, M. I. (2021, 12-14 de novembro). Custos no terceiro setor: Um panorama quantitativo e qualitativo da produção científica nacional [Apresentação da conferência]. XXV Congresso Brasileiro de Custos, Vitória, ES, Brasil.

Mañas, A. V., \& de Medeiros, E. E. (2012). Terceiro setor: um estudo sobre a sua importância no processo de desenvolvimento sócio-econômico. Perspectivas em Gestão \& Conhecimento, 2(2), 15-29.

Ministério da Educação Brasil (MEC). (2004, 16 de dezembro). Institui as diretrizes curriculares para o curso de graduação em ciências contábeis, bacharelado, e dá outras providencias [Resolução $\left.\mathrm{N}^{\circ} 10\right]$. Recuperado de http:// portal.mec.gov.br/cne/arquivos/pdf/rces0010_04.pdf [Consulta: 15 de setembro de 2017].

Ministério da Educação Brasil (MEC). (2021). Cadastro Nacional de Cursos e Instituiçóes de Educação Superior. Cadastro e-MEC. Ministério da Educação. Instituiçóes de Educação Superior e Cursos Cadastrados. Recuperado de http://emec.mec.gov.br/ [Consulta: 15 de setembro de 2017]. 
Olak, P. A., \& Nascimento, D. T do. (2010). Contabilidade para entidades sem fins lucrativos (terceiro setor). São Paulo: Atlas.

Oliveira, J. F. de, Libâneo, J. C., \& Toschi, M. S. (2017). Educação escolar: políticas, estrutura e organização. São Paulo: Cortez Editora.

Paes, J. E. S. (2004) Fundaçóes e entidades de interesse social: aspectos jurídicos, administrativos, contábeis e tributários. Brasília: Brasília Jurídica.

Peléias, I. R., Silva, G. P. D., Segreti, J. B., \& Chirotto, A. R. (2007). Evoluçáo do ensino da contabilidade no Brasil: Uma análise histórica. Revista Contabilidade \& Finanças, 18(SPE), 19-32. https://doi.org/10.1590/ S1519-70772007000300003

Piza, S. C. T., Parisi, C., Megliori, E., \& Gallo, M. F. (2012). A aderência das práticas contábeis das entidades do Terceiro Setor às normas brasileiras de contabilidade: um estudo multicaso de entidades do município de São Paulo - SP. Revista de Contabilidade do Mestrado em Ciências Contábeis da UERJ, 17(3), 79-97.

Poder Legislativo Brasil. (1996, 7 de junho). Autoriza o exmo Sr. Governador Amazonino Mendes a ausentar-se do pais [Decreto Legislativo $\mathrm{N}^{\circ} 456$ ]. Recuperado de https://www.lexml.gov.br/urn/urn:lex:br;amazonas:es tadual:decreto.legislativo:1996-06-07;456 [Consulta: 15 de setembro de 2017].

Portulhak, H., Delay, A. J., \& Pacheco, V. (2015). Prestação de contas por entidades do terceiro setor e seus impactos na obtenção de recursos: Um olhar sobre o comportamento dos doadores individuais. Pensar Contábil, 17(64), 39-47.

Presidência da República Brasil. (1850, 25 de junho). Código Comercial [Lei No 556]. Recuperado de http://www.planalto.gov.br/ccivil_03/Leis/LIM/ LIM556compilado.htm\#: :text=L0556\%2DCompi lado\&text=LEI\%20N\%C2\%BA\%20556\%2C\%20 DE\% 2025\%20DE\%20JUNHO\%20DE\% 20 1850.\&text=Art.,nelas $\% 20$ possua $\% 20$ parte $\% 20$ ou\%20interesse [Consulta: 15 de setembro de 2017].

Presidência da República Brasil. (1860, 22 de agosto). Contendo Providencias sobre os Bancos de Emissão, Meio Circulante e Diversas Companhias e Sociedades [Lei No 1.083]. Recuperado de http://www.planalto.gov.br/ ccivil_03/leis/lim/lim1083.htm [Consulta: 15 de setembro de 2017].

Presidência da República Brasil (1951, 31 de julho). Inclui, no Curso de Ciências Econômicas, a Cadeira de História Econômica Geral e do Brasil, e Desdobra o Curso de Ciências Contábeis e Atuariais [Lei No 1.401].

Presidência da República Brasil (1961, 20 de dezembro). Lei de Diretrizes e Base de 1961 -. Fixa as Diretrizes e Bases da Educação Nacional [Lei No 4024/61]. Recuperado de https://presrepublica.jusbrasil.com.br/ legislacao/108164/lei-de-diretrizes-e-base-de-1961-lei4024-61\#: : :text=Fixa\%20as\%20Diretrizes\%20e\%20 Bases\%20da\%20Educa\%C3\%A7\%C3\%A3o\%20

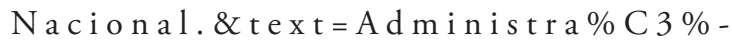
A $7 \%$ C $3 \%$ A 3 o \% 20 d o \% 20 Ensino,Art.,Par\%C3\%A1grafo\%20\%C3\%BAnico [Consulta: 15 de setembro de 2017].

Presidência da República Brasil. (2014, 17 de março). Estabelece o Regime Jurídico das Parcerias entre a Administração Pública e as Organizaçóes da Sociedade Civil [Lei No 13.019]. Recuperado de www.2camara. leg.br/legin/fed/lei/2014/lei-13019-31-julho2014-779123-publicacaooriginal-144670-pl.html [Consulta: 28 de setembro de 2017].

Quinn, M., \& Hiebl, M. R. (2018). Management accounting routines: A framework on their foundations. Qualitative Research in Accounting \& Management, 15(4), 535-562. https://doi.org/10.1108/QRAM-052017-0042

Romoaldo, T. P. T., \& dos Santos, J. J. A. (2020). Entendida contabilidade no terceiro setor: estudo de caso. Revista Livre de Sustentabilidade e Empreendedorismo, 5(5), 5-26.

Salamon, L. M., \& Anheier, H. K. (1992). In search of the non-profit sector. I: The question of definitions. 
Voluntas: International Journal of Voluntary and Nonprofit Organizations, 3(2), 125-151. https://doi. org/10.1007/BF01397770

Salamon, L. M., \& Anheier, H. K. (1993). A comparative study of the non-profit sector: purposes, methodology, definitions and classifications. In S. Saxon-Harrold \& J. Kendall (Eds.), Resarching the voluntary sector (pp. 179-195). Tonbridge: Charities Aid Foundation.

Schmidt, J. P. (2017). Universidades comunitárias e terceiro setor: fundamentos comunitaristas da cooperação pública. Santa Cruz do Sul: Edunisc.

Scott, W. R. (1995). Institutions and organizations. Foundations for organizational science. London: Sage Publications.

Silva, C. E. G., \& Aguiar, A. C. (2011). Avaliação de atividades no terceiro setor de Belo Horizonte: da racionalidade subjacente às influências institucionais. Organizaçōes \& Sociedade, 18(56), 35-56. [Consulta: 15 de setembro de 2017]. https://doi.org/10.1590/ S1984-92302011000100002

Silveira, D., \& Borba, J. A. (2010). evidenciação contábil de fundaçóes privadas de educação e pesquisa: Uma análise da conformidade das demonstraçôes contábeis de entidades de Santa Catarina. Contabilidade Vista \& Revista, 21(1), 41-68.

Soares, S. V., Richartz, F., De Lima Voss, B., \& De Freitas, C. L. (2012). Evolução do currículo de Contabilidade no Brasil desde 1809. Revista Catarinense da Ciência Contábil, 10(30), 27-42. https://doi.org/10.16930/22377662/rccc.v10n30 p27-42

Sousa Araújo, T., Araújo Leal, E., \& Ferreira Lourenço, R. (2021). Expectativas e satisfação dos discentes sobre os saberes e competências requeridas dos docentes na área de ciências contábeis. Revista Ambiente Contábil 13(1), 324-342. https://doi.org/10.21680/2176-9036.2021v13n1 ID20179
Souza, F. G. de, Barros, D. de O., Celis, L. M. M., \& Araújo, J. C. O. (2021). Higher education in the IPSAS implementation process: A comparative study between Brazil and Mexico. Research, Society and Development, 10(9), e19510918059. https://doi.org/10.33448/rsdv10i9.18059

Souza, F. G., Paixão, J., \& Mayer, L. T. (2020). Proposta de jogo sobre a estrutura conceitual do setor público uma ferramenta aplicada a UFPE. Revista Evidenciação Contábil \& Finanças, 8(2), 74-90. https://doi.org/10.22478/ufpb.2318-1001.2020v8n 2.45155

Souza, F. J. V., Dantas, E. B., Araujo, A. O., \& Silva, M. C. (2012). Prestação de contas no terceiro setor: Uma análise das entidades possuídoras do título de utilidade pública federal no estado do Rio Grande do Norte. Revista ConTexto-UFRGS, 12(21), 105-116.

Vergara, S. C. (2006). Projetos e relatórios de pesquisa. São Paulo: Atlas.

Yazdifar, H., Zaman, M., Tsamenyi, M., \& Askarany, D. (2008). Management accounting change in a subsidiary organisation. Critical Perspectives on Accounting, 19(3), 404-430. https://doi.org/10.1016/j. cpa.2006.08.004

Zittei, M. V. M., Politelo, L., \& Scrapin, J. E. (2016). Nível de evidenciação contábil de organizaçôes do terceiro setor. Revista de Administração Pública e Gestão Social, 8(2), 85-94. https://doi.org/10.21118/apgs.v1i2.892

Fecha de recepción: 26 de noviembre de 2019 Fecha de aceptación: 10 de octubre de 2020 Correspondencia: caspufpe@gmail.com alexsandroromao@ig.com.br jesseovidio@gmail.com 